\title{
Meritocracia e gestão de pessoas por competências: tema utópico ou realidade organizacional?
}

\author{
ALMIR ROgÉRIO dA SILVA SOUZA ${ }^{1}$ \\ ISABELLA Francisca Freitas GoUveia de VASCONCELOS ${ }^{2}$ \\ 1 PESQUisador AUtÔNOMO, RIO DE JANEIRO - RJ, BRASIL \\ ${ }^{2}$ PESQUISADORA AUTÔNOMA, CAMPINAS - SP, BRASIL
}

\begin{abstract}
Resumo
Neste trabalho se realiza uma revisão de literatura sobre o valor meritocracia nas sociedades contemporâneas e nas organizações. Relacionamos o valor meritocracia a um modelo de gestão de pessoas baseado em competências (modelo estratégico de gestão de pessoas), onde são definidos objetivos e metas claras de forma transparente com equipes de trabalho e indivíduos e realizada uma avaliação de desempenho segundo critérios claros previamente estabelecidos e, quando apurado o mérito, o mesmo é reconhecido com base em remuneração diferenciada para indivíduos e equipes, além de ser reconhecido o mérito de forma simbólica. Ressalta-se que um sistema meritocrático e uma gestão por competências reforçam o sentimento de justiça social nas organizações e equidade e as relações de confiança no sistema. Depois de realizada uma pesquisa, onde foram entrevistados 17 executivos alunos do Mestrado Profissional em Administração, em uma organização de ensino de excelência, constatou-se que 53\% dos mesmos trabalham em empresas consideradas meritocráticas por eles e $36 \%$ em empresas parcialmente meritocráticas e 11\% em empresas onde não existe nenhum reconhecimento de mérito. Analisaram-se as causas destes resultados, propondo-se soluções para o aprimoramento destes sistemas.
\end{abstract}

Palavras-chave: Meritocracia. Equidade. Gestão de Pessoas por Competências. Confiança.

\section{Meritocracy and competency-based people management model: utopia or organizational reality?}

\begin{abstract}
Our literature review is based on the definition of meritocracy in contemporary societies and organizations. We relate meritocracy to competencybased people management model (strategic people management model), where clear objectives and goals are defined transparently with teams and individuals, and conducting performance evaluation according to previously established criteria. When merit is determined, it is recognized both symbolically and through differentiated remuneration for individuals and teams. It is emphasized that a meritocratic system and competence management reinforces the sense of social justice in organizations and equity and trust relations in the system. The research consisted of a survey with 17 executives, students of a master's degree program in business administration offered by a teaching organization of excellence. Results showed that $53 \%$ of them consider their companies meritocratic, $36 \%$ considered their companies partially meritocratic, and $11 \%$ consider that the organization they work for does not recognize meritocracy. The study discusses these results, proposing solutions for the improvement of people management systems.
\end{abstract}

Keywords: Meritocracy. Equity. Competency-Based People Management Model. Trust.

\section{Meritocracia y gestión de personas por competencias: ¿ tema utópico o realidad organizativa?}

\section{Resumen}

En este trabajo se realiza una revisión de la literatura sobre el valor meritocracia en las sociedades contemporáneas y en las organizaciones. Relacionamos el valor meritocracia con un modelo de gestión de personas basado en competencias (modelo estratégico de gestión de personas) donde se definen objetivos y metas claras de manera transparente con equipos de trabajo e individuos y se realiza una evaluación de desempeño de acuerdo con criterios claros previamente establecidos y, una vez determinado el mérito, se reconoce mediante una remuneración diferenciada a individuos y equipos, además del reconocimiento simbólico. Se enfatiza que un sistema meritocrático y una gestión por competencias refuerzan el sentido de justicia social y equidad en las organizaciones y las relaciones de confianza en el sistema. Después de realizar una encuesta con 17 ejecutivos, alumnos del máster profesional en Administración de Empresas de una organización de enseñanza de excelencia, se constató que el 53\% considera que trabaja en empresas meritocráticas; el 36\%, en empresas parcialmente meritocráticas; y el 11 \% en empresas donde no hay reconocimiento de mérito. Se analizaron las causas de estos resultados y se propusieron soluciones para la mejora de estos sistemas.

Palabras clave: Meritocracia. Equidad. Gestión de personas por competencias. Confianza. 


\section{INTRODUÇÃO}

No presente artigo, vamos discutir e analisar como é utilizado o modelo de gestão por competências e sua real contribuição para produzir uma maior meritocracia, na visão dos entrevistados, nas organizações em que eles trabalham.

A meritocracia é um constructo que tem um embasamento teórico, de acordo com teorias organizacionais vigentes e que são um pano de fundo para a sua aplicação. Não é um tema de discussão fácil, pois envolve uma série de fatores que estão interligados e promovem uma constante análise diante da eficácia da sua aplicabilidade ou não.

Meritocracia existe nas organizações no Brasil neste momento de crise econômica e moral das instituições? Trata-se de um tema polêmico e por isso mereceu ser objeto de estudo.

\section{Gestão estratégica de pessoas e competências}

Nos dias atuais, dentro das organizações e de suas áreas, a estratégia tem ocupado um papel de destaque, principalmente na elaboração de processos e meios que buscam o desenvolvimento organizacional, buscando alinhar todos os envolvidos (os atores do contexto). Nesse modelo, a Gestão de Pessoas tem um papel chave, por meio da fundamentação téorica da Gestão Estratégica de Pessoas, tendo em vista que não há possibilidade de desenvolvimento organizacional que não possa envolver os indivíduos que ali trabalham diariamente, levando em consideração o alinhamento de interesses, aumento do grau de motivação e desenvolvimento de incentivos baseados no mérito, para que o indivíduo atenda ao cumprimento dos objetivos organizacionais (Zanini, 2009).

A competência é forma de utilizar a inteligência de forma que desenvolva o conhecimento adquirido por meio da prática de envolver recursos que gerem valor econômico para organização e valor social para o indivíduo, mas com a intenção do indíviduo de gerar uma solução para o problema apresentado (Fleury, 2002; Zarifian, 1999).

Ao conceito de competência podemos incorporar o da entrega. Dutra (2001) desenvolveu esse conceito, onde as pessoas possuem conhecimentos, habilidades e atitudes (CHA). Entende por entrega aquilo que o indivíduo quer ofertar a organização, de forma responsável (Dutra, 2001). Fala-se em competência. Em se tratando do conceito meritocracia, uma questão que se coloca atualmente é se há sentido em se tratar deste tema atualmente.

\section{Meritocracia}

A meritocracia é um conjunto de valores (no nível ideológico) que requisita que o indivíduo inserido na sociedade, obtenha a sua posição conforme o mérito das suas ações individuais, ou seja, o reconhecimento público da sua capacidade qualitativa de realização própria (Barbosa, 2003).

É um tópico de alta complexidade dentro da cultura organizacional brasileira, por se tratar de um tema com larga discussão acadêmica e que afeta de forma direta (objetiva ou subjetiva) na correta interpretação quanto à profundidade e extensão do seu conceito. Basicamente é visto como um sistema de gestão e avaliação para a obtenção de um ganho em função do resultado individual de uma tarefa e que pode ser utilizada também como forma de ascensão na hierarquia organizacional.

O mérito é um meio de conceder de forma igual a todo individuo que quer demonstrar a sua capacidade de realização produtiva por meio da "inteligência, talento e empenho" para destacar-se em um grupo, de acordo com a sua força de realização e de atingimento acima do esperado das metas estipuladas. Ideia totalmente contraria àquela que se deve oferecer as oportunidades para um indivíduo somente por sua classe social ou hereditariedade familiar.

\section{Sistemas meritocráticos e ideologia da meritocracia}

Uma sociedade igualitária se conquista com a capacidade de preservar direitos que possibilitem a conquista e reconhecimento, diante de indivíduos livres e iguais, independente de classes, gêneros, etnias etc. Dar acesso igual às oportunidades e condições de ascensão social por meios próprios e de suas características intrínsecas para superar as dificuldades e atingir os seus objetivos, é uma forma de garantir, aos indivíduos, uma meritocracia na organização (Barbosa, 2003; Bobbio, 1997). 
Usando-se dessa ideologia meritocrática, todo o indivíduo que se destacar dentro de um grupo social será reconhecido por meio do mérito - e terá a possibilidade de conquistar uma posição dentro desse grupo, por meio do acesso a um cargo ou posição mais alta, com mais atribuições e responsabilidades, um pacote de benefícios melhor e um ganho de reputação e status funcional.

Essa política tem o poder de influenciar aqueles que ainda não foram distinguidos, porque exerce uma força de motivação diante da possibilidade do acesso a algo exclusivamente pelo seu mérito, pelo seu esforço pessoal. A ideologia meritocrática será validada por meio de uma isonomia de avaliação e de reconhecimento.

Um sistema democrático de direito terá na equidade uma condição sine qua non, isto é, todos os membros de uma mesma sociedade terão os mesmos direitos perante a lei. Por isso, um sistema meritocrático tem tanta força e sendo um atributo indispensável de uma sociedade democrática, pois oferta a todos os indivíduos as mesmas chances de conseguir se destacar dentro de critérios previamente estabelecidos e cientes por todos. Rechaça qualquer possibilidade de manter o acesso as oportunidades a um grupo diminuto e protegido, que por diversas vezes não atende aos critérios mínimos pré-estabelecidos.

Uma pergunta sempre ronda o processo meritocrático: Como garantir que "todos" tenham as mesmas condições de desenvolvimento sociocultural e que somente as capacidades intrínsecas e a competência sejam avaliadas no processo de competição?

A transparência ao longo do processo é fundamental, assim como a equidade é um valor inquestionável para aferir de forma real e isonômica, todo o processo de avaliação e que o mérito seja a única forma de desempate. Nas sociedades modernas e igualitárias, a meritocracia é um sistema essencial para atingir os objetivos e anseios dos seus indivíduos (Barbosa, 2003). Que nenhuma outra forma de opressão e pressão (proximidade, hierarquia e influência) seja utilizada. Será que a meritocracia pode parecer uma ideologia "utópica" atualmente?

\section{Meritocracia e gestão de pessoas por competências}

Existe a hipótese que o modelo de Gestão de Pessoas por Competências, quando introduzido em uma organização, é capaz de produzir uma maior meritocracia, em função das suas práticas organizacionais, visto que, a competência é uma forma de se avaliar o indivíduo.

Barney (1991) desenvolveu a Teoria dos Recursos da Firma (RBV - Resource Based View) com base em uma definição que as organizações contemporâneas são um conjunto de recursos. Esses recursos (capital financeiro, físico, humano e organizacional), em um mundo globalizado não são mais um diferencial competitivo. O que acaba sendo um diferencial são as vantagens competitivas que são difíceis de imitar pela concorrência. Porém, o mesmo Barney afirma que uma vantagem competitiva deixa de sê-la, se um concorrente consegue imitá-la.

A teoria de Barney encontra sinergia com o conceito de Competências Essenciais (Core Competences) de Prahalad e Hamel (1990).

Onde uma organização deve desenvolver competências essenciais e que devem ser difíceis de serem imitadas pelo mercado.

As competências essenciais servirão como alicerce para a vantagem competitiva da organização, nas suas diversas área de atuação, onde uma mudança em qualquer cenário (interno ou externo) acarretará numa mudança ou adaptação pela organização, esse conceito também é chamado de capacidades dinâmicas (dynamic capabilities) (Leonard-Barton, 1992). A vantagem competitiva também pode ser adquirida por meio da inovação, onde uma reconfiguração das capacidades dinâmicas podem produzir serviços e produtos inovadores e/ou diferenciados (Teece, 1992). Essas mudanças também afetarão os indivíduos, pois os mesmos precisaram desenvolver ou lapidar novas competências essenciais para o desenvolvimento das suas atividades, por meio de novos conhecimentos, habilidades e atitudes (CHA).

São mais sensíveis ao efeito da competência, os processos que criam e estimulam o desenvolvimento dos indivíduos na organização como forma de crescimento profissional (Dutra, 2004). Nessa linha, a evolução dos indivíduos dentro das organizações passa pela identificação individual das competências essenciais e de que forma a organização irá mantê-los motivados, visto que, a capacidade de trabalhar com desafios está diretamente ligada à capacidade organizacional de ter um sistema meritocrático ativo e real. Que os indivíduos tenham uma avaliação de desempenho cujo ideal é ser totalmente isonômica. Os profissionais que mais se destacarem diante das mudanças organizacionais e que sua entrega reverta em resultados 
esperados, sejam devidamente reconhecidos, por meio de uma premiação, ganho salarial ou até de uma promoção. O importante é ter um sistema meritocrático claro e com regras acessíveis a todos os integrantes da organização, pois reforça a credibilidade e confiança de todos no modelo de Gestão por Competências.

\section{Confiança como ativo intangível de uma empresa}

A confiança é um ativo intangível de valor inestimável, tanto nas relações individuais quanto nas relações empresariais. A confiança só poderá existir na relação de no mínimo duas figuras, que podem ser tanto física quanto jurídica, nas suas configurações diversificadas.

Luhmann (1996), na sua Teoria de Estruturação Social, diz que a confiança pode ser de três tipos: (1) a processual, (2) a baseada em características e (3) a institucional.

Confiança está nas relações dos contratos de trabalho, onde são observados comportamentos eticamente justificáveis, entre os membros de uma organização (verticais e horizontais), entre relações moralmente justificáveis, dando credibilidade a um sistema ou pessoa, expressando a boa fé no outro, sem tomar uma vantagem excessiva nessa relação de interesse conjunto ou troca econômica (Cummings \& Bromiley, 1996; Giddens, 1991; Hosmer, 1995; Zanini, 2016).

É um complemento importante e que fortalece as interações corporativas. As relações de confiança promovem uma maior cooperação entre os indivíduos e coordenação entre as áreas organizacionais. Funciona como uma ferramenta de liderança e gestão de pessoas.

Todo o ambiente é contaminado por uma dinâmica mais produtiva. Há um engajamento de maior confiança dos indivíduos na cultura organizacional, pois existe uma redução de riscos de confrontos, por meio de uma relação de interdependência. Toda a organização é beneficiada por processos mais transparentes e dinâmicos.

A sociabilidade se manifesta de forma positiva, afetando as burocracias, visto que são menos tensas e mais fluídas. Existe uma maior flexibilidade dentro dos processos organizacionais, onde as cooperações mútuas das relações interpessoais se fazem presente dentro da cadeia organizacional.

Confiança é construída ao longo do tempo e não abre espaço para o imediatismo, uma vez que é relacional e cultivada por princípios de justiça e compartilhamento mútuo, onde é relevante a interação entre dois ou mais envolvidos que elaboram normas e preceitos de acordos com regras bem definidas e pontuais. Toda essa complexidade influenciará o ambiente organizacional nas suas tomadas de decisões.

Um dos pilares que suportam a ideologia de um sistema meritocrático é a confiança em todo o processo, porque para total aderência e credibilidade no mérito, há a necessidade de todos os envolvidos estarem empenhados para que exista uma forma de avaliação de desempenho.

Não existe a possibilidade de isonomia de um sistema meritocrático, onde há falta de confiança pelos indivíduos nas regras estipuladas. Existe a necessidade de consenso entre a organização e os indivíduos sobre todas as regras. Se isso não houver, a adesão dos grupos funcionais não irá acontecer e todo o processo não trará os benefícios esperados, devido a não credibilidade no processo de avaliação. Um sistema meritocrático, sem a confiança de todos, não pode produzir um resultado esperado diante dos envolvidos que desconfiam de todo o processo de avaliação.

\section{Gestão por confiança}

Uma gestão para ser eficiente necessita criar várias condições que sejam favoráveis para a meta que deseja ser alcançada. A confiança tem destaque fundamental, porque está pontualmente relacionada com o lado interpessoal dos indivíduos envolvidos e o seu desempenho esperado.

Estudos diversos demonstram que existe correlação entre o constructo confiança e desempenho, tendo como observação e foco de análise, os envolvidos no processo de gestão e seus detalhes, onde determinam a necessidade de se expandir e aprofundar sobre esse constructo, suas particularidades, detalhes e influências dentro do universo organizacional (Araujo \& Cançado, 2013; Kawai, 2017; Krot \& Lewicka, 2012; Zanini \& Migueles, 2014). 
O constructo meritocracia tem evoluído na direção da obtenção de destaque dentro das ciências sociais, tais como sociologia, antropologia, psicologia, economia e administração (Fukuyama, 1996; Giddens, 1991; Kramer \& Tyler, 1996; Lane, 1996; Luhmann, 1980; Tzafrir \& Harel, 2002; Zand, 1972; Zanini, 2016).

Há a necessidade de ter um grau elevado de confiança entre os líderes e seus subordinados, dado que a integração de todos levará a um alto nível de união das equipes que buscam chegar aos objetivos organizacionais propostos pela alta direção.

Confiança é relacional, e por isso trabalha o lado emocional e cognitivo de todos os presentes no contexto analisado, já que demanda uma interação visceral que excede a pura lógica da razão (Ripperger, 1998; Zanini, 2016).

Não há forma de desprezar, em uma relação de confiança, a tomada de riscos, dado que a confiança pode promover a solução de problemas entre as partes, mas pode também minimizar possíveis conflitos que não seriam solucionados se ambas as partes não assumissem na confiança um elemento-chave na comunicação entre a organização e os indivíduos que fazem parte de todo o processo. É importante pontuar que a confiança parte da ideia que uma promessa será devidamente cumprida, pela fidelidade e lealdade de alguém diante do seu compromisso com a outra parte (Duluc, 2000).

Sempre haverá a presença do risco nessa interação entre as partes. Não há possibilidade de ter uma ideia descompromissada, pois o risco é real na sua forma mais simplória, isto é, a confiança requer ciência do risco envolvido por todas as partes envolvidas no processo (Zanini \& Migueles, 2014).

A gestão de confiança gerará os caminhos para que uma organização ao implementar um sistema meritocrático seja capaz de produzir métodos de avaliação de desempenho claros e eficientes, pois as relações ocorrem sempre dentro de um contexto social (Zanini, 2016). É importante que todos os indivíduos envolvidos no processo de reconhecimento e crescimento profissional tenham a confiança na transparência das regras, avaliações e decisões finais.

\section{Meritocracia e confiança}

A meritocracia e a confiança são um investimento de longo prazo, mas que são cultivados no presente e com a aprovação dos envolvidos para que todos estejam a par do papel de cada ator no contexto social (Barbosa, 2003; Zanini, 2016).

Nas organizações que introduziram de forma eficaz e praticam realmente um sistema meritocrático de crescimento profissional e de remuneração, se confirma uma maior confiança na organização e nas suas crenças empresariais, pois há a possibilidade de encurtar as diferenças sociais (Sandel, 2014).

A confiança tem um papel preponderante dentro de um sistema meritocrático, porque está relacionada com o meio que conduzirá a partilha de saberes e das melhores práticas pela organização junto aos seus colaboradores que estão almejando e se destacam para que sejam reconhecidos e tenham a valorização profissional almejada. A contribuição de todos se dará de forma global, em função das demandas e necessidades da organização, por meio de um ativo de grande valor e intangível (Zanini, 2016).

A percepção de meritocracia na organização é reforçada com uma gestão de pessoas por competências mais eficazes, criando mais confiança de todos os indivíduos na liderança e na gestão da organização. Reforça ainda os laços de confiança no trabalho coletivo (entre áreas distintas ou entre pessoas de uma mesma área).

Há uma percepção de maior justiça distributiva no trabalho, quando um sistema meritocrático é bem aplicado e acessível a todos os indivíduos que compõem a organização.

\section{METODOLOGIA}

Antes de expor os tópicos metodológicos aplicados neste estudo, é importante trazer a questão problemática e o objetivo do referido estudo de caso, para comprovar o que está sendo analisado pontualmente.

A proposta deste trabalho, em linha com a sua problemática: Na visão dos executivos entrevistados, existe ou não meritocracia nas empresas em que trabalham e se isto está relacionado à implementação de gestão de pessoas por competência sua empresa? E o seu objetivo de pesquisa: Compreender se na visão dos executivos, em suas trajetórias de carreira, existe maior meritocracia nas empresas quando estas implementam o modelo de gestão de pessoas por competências. 
Para a produção deste trabalho foi feita a escolha metodológica da pesquisa qualitativa, fundamentada na análise do estudo de caso e levantadas através das técnicas de coleta de dados como: análise documental primária, análise documental secundária e entrevistas semiestruturadas.

A pesquisa qualitativa se apropria de diversas formas de apuração investigativa dos fatos pesquisados, onde tem um caráter descritivo, dentre elas, estudo de caso (pesquisa), a etnografia, a pesquisa documental, entre outras (Creswell, 2014; Godoy, 1995a).

Godoy (1995a) ressalta os conceitos por meio da citação de quatros características básicas: a) A pesquisa qualitativa tem o ambiente natural como fonte direta de dados e o pesquisador como instrumento fundamental; b) A pesquisa qualitativa é descritiva; c) $O$ significado que a pessoas dão às coisas e à sua vida é a preocupação essencial do investigador; d) Pesquisadores utilizam o enfoque indutivo na análise de seus dados (Godoy, 1995a, pp. 62-63).

Na pesquisa qualitativa, a pesquisa documental pode ser de fonte primária (quando produzida pelas pessoas ou organizações que vivenciaram o fato estudado) e de fonte secundária (quando as pessoas e ou organizações que narram os fatos não estavam presentes no momento do seu acontecimento), porém tem relevância na análise de conteúdo do material pesquisado (Godoy, 1995b). Sua singularidade está no trabalho de campo que é realizado para obtenção dos dados.

O estudo de caso é uma forma de pesquisa que se caracteriza pelo objeto que é profundamente analisado, dentro de um contexto contemporâneo da vida real, sendo empírica, mas não deixando de se atentar para a clareza dos limites entre o contexto e o fenômeno, porém se concentra na compreensão da dinâmica que está presente nos métodos de coleta de dados (Creswell, 2014; Eisenhardt, 1989; Godoy, 1995b; Yin, 2015).

A pesquisa de campo tem como objetivo básico reunir dados e/ou informações sobre um determinado problema, onde se busca uma resposta para comprovar uma hipótese ou descobrir novos fenômenos que são inerentes ao objeto de estudo (Marconi \& Lakatos, 2003). As entrevistas semiestruturadas seguiram um roteiro que foi sendo ajustado conforme a evolução da análise do material coletado, porém de forma bem flexível, dando a possibilidade que o entrevistado pudesse fazer as inserções que achasse necessário e relevante diante do tema estudado.

Esta pesquisa foi realizada em uma organização de ensino superior de alta qualidade, pioneira na implantação do curso de administração no Brasil, tendo na excelência acadêmica um dos seus diferencias, junto aos alunos de um determinado Mestrado Profissional em Administração, que possuem o mesmo perfil sociocultural, apesar da sua rica diversidade. Trabalham em grandes empresas nacionais e internacionais, onde já existe a implantação de um sistema de gestão de pessoas por competências e que o constructo meritocracia já está inserido dentro das suas periódicas avaliações de desempenho.

Inicialmente foram convidados 30 alunos do referido Mestrado Profissional. Os convites foram realizados por contato pessoal e/ou enviados através de mídia social, para participarem de uma pesquisa empírica, por meio de uma entrevista semiestruturada, porém, em função da relevância do tema estudado, a meritocracia, nem todos quiseram participar, alegando que apesar do anonimato apresentado na abordagem inicial, não queriam expor a sua organização ou a si mesmo.

Aceitaram participar da pesquisa 23 alunos, sendo que 19 confirmaram a participação, mas somente 17 alunos se colocaram disponíveis para serem entrevistados. Para efeito de ética em pesquisa, não serão divulgados os nomes dos entrevistados, mantendo o anonimato e a preservação de suas identidades.

Desde já se assume que a pesquisa é interpretativa, com isso ela não será neutra ou imparcial, mesmo buscando uma distância na interpretação dos fatos e dados expostos, a interação sujeito-sujeito, com referência ao conhecimento fenomenológico, sempre haverá um determinado grau de parcialidade na análise e este será um dos limites desta pesquisa. 


\section{APRESENTAÇÃO DOS DADOS COLETADOS}

Foram realizadas 17 entrevistas semiestruturadas, no período de 22 de junho de 2017 até o dia 25 de julho de 2017, sendo ao vivo e por Skype, tendo sido todas elas gravadas e transcritas integralmente, para facilitar a análise do seu conteúdo.

Para manter o anonimato, cada entrevistado recebeu um código e após a conclusão das entrevistas, foram definidos cinco perfis para ajudar na análise do conteúdo, e que são: (1) idade; (2) escolaridade; (3) formação; (4) cargo/função e (5) gênero. Após as entrevistas terem sido analisadas, elas foram categorizadas, conforme o escopo de pesquisa. Chegou-se a cinco categorias, e que são:

Quadro 1

Categorias e significados

\begin{tabular}{|c|c|}
\hline Categorias & Significado \\
\hline Categoria 1 & $\begin{array}{r}\text { Importância do mestrado na carreira doentrevistado } \\
\text { (opinião sobre o curso). }\end{array}$ \\
\hline Categoria 2 & $\begin{array}{r}\text { Posição do entrevistado sobre a Meritocracia } \\
\text { (conceito e visão dentro da sua empresa). }\end{array}$ \\
\hline Categoria 3 & $\begin{array}{r}\text { Opinião do entrevistado sobre a Gestão } \\
\text { de Competências na sua empresa. }\end{array}$ \\
\hline Categoria 4 & $\begin{array}{r}\text { Posição do entrevistado sobre a Meritocracia } \\
\text { na sua empresa (o que pode ser melhorado). }\end{array}$ \\
\hline Categoria 5 & $\begin{array}{r}\text { Posição do entrevistado sobre a Confiança } \\
\text { no sistema meritocrático da sua empresa. }\end{array}$ \\
\hline
\end{tabular}

Fonte: Elaborado pelo autores.

Para cada entrevista, foi criado um fichamento com base nas categorias previamente determinadas pela análise de conteúdo dos dados.

\section{ANÁLISE DAS ENTREVISTAS E GRUPOS ENCONTRADOS}

Após a análise individual dos fichamentos elaborados em função do conteúdo apresentado, identificou-se 4 grupos, conforme abaixo:

\section{Grupo 1 - Entrevistados 01, 02 e 07}

Posicionamento: A meritocracia e gestão por competências estão presentes; mas para os entrevistados, não existe percepção de justiça, devido a forma como a remuneração diferenciada (bônus) é calculada, e também como é atribuído o mérito simbólico, gerando uma percepção de injustiça e competição extrema entre os indivíduos.

Eles acreditam que a meritocracia está correlacionada a uma gestão de pessoas por competências, esse grupo representa aproximadamente $18 \%$ dos entrevistados. Porém nas empresas em que trabalham, a meritocracia é aplicada parcialmente, de acordo com percepção dos entrevistados, é aplicada a curva forçada de Harvard na obtenção de conceitos de performance $(A-20 \%$ dos colaboradores considerados os melhores; $B-30 \%$ considerados os muito bons; $C-20 \%$ sendo considerados bons; $D-15 \%$ são os regulares e $E-15 \%$ dos últimos não recebem bônus nenhum por não terem cumprido com os resultados apresentados). 


\section{Grupo 2 - Entrevistados 03, 06, 08, 10, 11, 13, 14, 16 e 17}

Posicionamento: Esse grupo é dos entrevistados que acreditam na meritocracia em conjunto com a gestão de pessoas por competências nas organizações. Trabalham em organizações que aplicam o constructo meritocracia como forma de avaliação de desempenho e ganho de confiança. Há uma maior percepção de justiça diante dos métodos aplicados por todos os envolvidos na organização.

Existem nas suas organizações regras claras e objetivas e de acesso a todos quanto aos meios de reconhecimento meritocrático, conforme a entrega individual, onde são reconhecidos por meio de bônus extra, aumento salarial, reconhecimento formal dentro da organização. $O$ sentimento e percepção de justiça estão presentes e são inerentes a todos que estão sendo avaliados.

Um detalhe que chama atenção é que $78 \%$ dos entrevistados desse grupo tem mais de 30 anos e ocupam cargos de gerência e diretoria em empresas de grande porte. Esse grupo representa 53\% dos entrevistados. Somando-se os grupos 1 e 2 , chega-se ao montante de $71 \%$ dos entrevistados trabalham em empresas meritocráticas ou parcialmente meritocráticas.

\section{Grupo 3 - Entrevistados 04, 12 e 15}

Posicionamento: É o grupo que reconhece que a meritocracia está correlacionada com a gestão de pessoas por competências, trabalham em empresas que o constructo meritocracia é disseminado com regras e avaliações, mas no dia a dia das suas organizações, o que se acaba vivenciando é que as promoções e reconhecimentos são apenas por meio "da amizade" ou "políticas".

Os entrevistados trabalham em organização pública da área de Óleo e Gás e privada Familiar. Essa prática de gestão acaba sendo corrosiva, porque enfraquece o papel da meritocracia como meio de alavancar uma maior participação dos envolvidos na entrega dos seus resultados. O que acaba valendo é o famoso "QI" - quem indicou - e não o reconhecimento por um desempenho profissional excelente e que foi reconhecido com uma premiação pelo seu resultado. Esse grupo é composto por $18 \%$ dos entrevistados.

\section{Grupo 4 - Entrevistados 05 e 09}

Posicionamento: É o grupo dos céticos - não acreditam na meritocracia e acham o tema "fantasioso" e "idealista", principalmente nas organizações brasileiras. Na visão de grupo não existe a aplicação da meritocracia, apesar de muitas vezes existir no discurso e no papel. Trabalham em áreas Sindicais e públicas de Energia. Não creem que esse reconhecimento exista de forma real e pontual diante de cenários tão incertos.

\section{ANÁLISE DOS DADOS}

Neste trabalho, foi considerado que a noção de mérito está associada ao esforço para se atingir resultados especificados entre a gerência e cada colaborador da equipe. Segundo os resultados das entrevistas, não basta à empresa ter um sistema de gestão de pessoas estratégico ou ainda por competências, mesmo que este esteja bem estruturado, tendo uma avaliação de desempenho bem constituída, com a fixação de metas junto às equipes de trabalho ou junto aos colaboradores individualmente de forma transparente e bem definida e um sistema de avaliação coerente para apurar se estas metas foram atingidas e superadas ou não. A existência deste sistema é condição necessária, mas não suficiente para gerar um sentimento de equidade e justiça entre os colaboradores, o que geraria um ciclo positivo, onde os colaboradores se dedicariam cada vez mais à empresa por perceberem um sistema justo e correto baseado no mérito, o que aumentaria ainda mais a produtividade.

Para gerar este ciclo virtuoso, faz-se fundamental o sentimento de justiça na organização por terem as equipes e os colaboradores atingido ou superado as metas. Para este sentimento de justiça, segundo os entrevistados, é fundamental a forma como se calcula a remuneração pela produtividade e como se paga a mesma.

Para o grupo 1, a empresa deles fez um enorme investimento para ter um sistema de gestão de pessoas estratégico e por competências, tendo estruturado um plano de carreira coerente, possuindo um método claro e lógico de fixar metas e objetivos com equipes e indivíduos e apurar se o resultado foi atingido ou não. Mas, todo este esforço não gera o sentimento 
de justiça na empresa e o ciclo virtuoso do qual falamos. Existe a percepção de um sistema sim baseado em apurar de forma transparente o mérito dos indivíduos, mas um sistema que na forma de distribuir recompensas não é justo; com isso, segundo os entrevistados, tem a percepção que a forma de calcular o pagamento pelo atingimento de metas e de atribuir o reconhecimento simbólico é injusta por ser extremamente desigual e já forçar a divisão do grupo organizacional segundo a curva forçada de Harvard, percebida como trazendo desigualdade e sentimento de injustiça.

Assim, as empresas destes entrevistados investiram para terem um sistema meritocrático e profissional, baseado na gestão de competências e no mérito, mas ao traduzir este reconhecimento de forma concreta em remuneração e reconhecimento simbólico, gerou-se muita insatisfação e percepção de desigualdade. Dessa forma, a empresa não recebe os benefícios que deveriam vir de um sistema de gestão de competências, que teria de reforçar a identificação dos colaborares com a empresa, o aumento da produtividade, o sentimento de justiça e as relações de confiança. Sugere-se a estas empresas (segundo os colaboradores) de mudar a forma de pagamento e atribuição de reconhecimento simbólico, não mais calculando segundo a curva de Harvard e buscando outros métodos mais equitativos de traduzir em remuneração o atingimento das metas. Ao calcular os bônus, a empresa poderia fixar porcentagens do salário dos indivíduos ou ainda certo número de salários a serem recebidos por cada equipe ou por cada indivíduo, que gerasse a percepção de uma maior igualdade e equidade na distribuição dos benefícios, já sendo os salários diferenciados o que já permitiria uma diferenciação no reconhecimento individual.

Para o grupo 2, 53\% dos alunos entrevistados do Mestrado Profissional em Administração existe a percepção de justiça e meritocracia na empresa em que trabalham, gerando o ciclo virtuoso que reforça as relações de confiança no sistema. Encontramos aqui a correlação achada na teoria de gestão de pessoas. Tudo isso se deve também, além de um sistema consistente em fixar as metas e objetivos com equipes e indivíduos e apurar os resultados de forma transparente e clara, o pagamento pelo mérito e o reconhecimento simbólico é feito de uma forma que é percebida como mais equitativa. Calcula-se aqueles que atingiram as metas, os que atingiram as metas e as superaram e os que não atingiram, e calcula-se certo número de vezes o salário ( $2 X$ o salário, $3 X$ o salário, etc.) como bônus a ser recebido. Como os salários são diferenciados, a diferenciação se faz pela remuneração de cada um, e este sistema é percebido como mais justo. Estas empresas também distribuem a todos, aumentos salariais tendo em vista o crescimento da empresa como um todo.

Como nos mostra Zanini (2016) neste caso do grupo 2, a confiança sistêmica (o grau de confiabilidade que um indivíduo ou grupo de indivíduos percebe em um determinado sistema social, como uma organização), aumenta. A confiança sistêmica aumenta no caso do grupo 2 tendo em vista que a forma de remuneração e atribuição do reconhecimento simbólico é percebida como justa e equitativa, mesmo levando-se em conta as diferenças individuais.

Assim, a gestão por confiança produzirá os meios para que uma organização, ao adotar um sistema meritocrático, seja capaz de desenvolver ferramentas de avaliação de desempenho eficientes e que os profissionais envolvidos em qualquer processo de crescimento profissional tenham a confiança na lisura das regras, avaliações e decisões finais.

Como mostramos neste trabalho, o executivo global, conforme definido, trabalha em empresas multinacionais grandes que possuem seus processos de gestão de pessoas formalizados e bem definidos, trabalhando com pessoas de várias nacionalidades, falando vários idiomas, lidando bem com a diversidade cultural, possuindo cargo de gerência, viajando e coordenando equipes internacionais e tendo uma remuneração alta.

Estes executivos pertencem a uma elite que toma grandes decisões e influencia socioeconomicamente o país. Muitas vezes chamada de "elite tecnocrática", tendo em vista sua formação profissional de alto nível, eles trabalham em sua maioria no setor privado.

A pesquisa mostra que metade dos entrevistados que cursaram o Mestrado Profissional em Administração é de executivos globais que em sua maioria trabalham em empresas consideradas por eles como justas e meritocráticas, o que mostra um cenário positivo para estes profissionais.

No entanto, como vimos, no caso do grupo 1, apesar da empresa possuir um sistema formalizado de gestão por competências que apura de forma transparente e consistente o mérito, não há percepção de justiça social e geração do ciclo virtuoso de aumento da produtividade e reforço das relações de confiança na empresa devido ao sistema de curva forçada para calcular a remuneração e atribuir simbolicamente o mérito. As empresas destes entrevistados deveriam segundo eles mudar a forma de calcular a remuneração por mérito, evitando o sistema de curva forçada. São três os entrevistados neste caso. 
No caso do grupo 3, existe a gestão por competências do modelo estratégico de gestão de pessoas, e o pagamento e a atribuição do mérito são considerados justos, mas até um certo nível gerencial. A partir desse nível hierárquico, as promoções são percebidas como sendo devidas a critérios "políticos" e ligados "à amizade" e de forma coerente, notamos que os três entrevistados que se encontram nesta situação trabalham ou em uma grande empresa do setor público, onde existe concurso, remuneração por desempenho, mas também muitos funcionários indicados para cargos de confiança apenas por critérios políticos, ou ainda trabalham em empresas familiares, que nomeiam parentes dos proprietários para alguns cargos mais altos. A percepção dos entrevistados (dois dos quais são executivos globais) é que a meritocracia vai até certo ponto neste tipo de sistema, que, por natureza, é influenciado por critérios políticos ou de inserção familiar.

No caso do grupo 4, os dois entrevistados são céticos no que diz respeito ao país como um todo e acham que o problema é sistêmico no Brasil, principalmente neste momento histórico, onde o país vive uma crise econômica e política, onde todos os valores são questionados pelo combate à corrupção e observa-se que não estamos vivendo uma realidade baseada no mérito, nem no setor público e nem no setor privado, e as pessoas estão preocupadas apenas em sobreviver. Os dois entrevistados, um trabalha em um sindicato e o outro em uma grande empresa pública de Energia.

\section{Quadro 2 \\ Grupos e tipologia}

\begin{tabular}{|c|c|l|}
\hline Grupos & Entrevistados & \multicolumn{1}{c|}{ Tipologia } \\
\hline Grupo 1 & E01; E02; E07 & $\begin{array}{l}\text { A meritocracia está relacionada com a gestão por competências, avaliação de desempenho } \\
\text { transparente, pagamento diferenciado de acordo com a performance, trazendo maior } \\
\text { justiça na empresa. Necessidade de transparência organizacional. Na empresa deles existe } \\
\text { meritocracia, mas sem a percepção de justiça, por causa da curva forçada de Harvard. } \\
\text { (A- 20\%; B - 30\%; C - 20\%; D - 15\% e E - 15\%, mas que não recebe nada). }\end{array}$ \\
\hline Grupo 2 & $\begin{array}{c}\text { E03; E06; E08 } \\
\text { E10; E11; E13 }\end{array}$ & $\begin{array}{l}\text { Reconhecem que a meritocracia está ligada por gestão de competências e avaliação de } \\
\text { desempenho, segundo critérios explícitos e transparentes, tendo em vista objetivos fixados } \\
\text { anteriormente. A meritocracia e percepção de justiça existem na empresa deles, porque } \\
\text { todos recebem a mesma quantidade de salários como bônus, se atingirem as metas. }\end{array}$ \\
\hline Grupo 3 & E04; E12; E15 & $\begin{array}{l}\text { Admitem que a meritocracia esteja relacionada com a gestão de competências, mas na } \\
\text { empresa deles, não há uma percepção de justiça, porque a maioria das promoções é feita } \\
\text { de forma política e por amizade. }\end{array}$ \\
\hline Grupo 4 & E05; E09 & $\begin{array}{l}\text { São céticos e não acreditam em meritocracia. Acham o conceito fantasioso, principalmente } \\
\text { no Brasil. }\end{array}$ \\
\hline
\end{tabular}

Fonte: Elaborado pelo autores.

\section{Resposta à problemática}

Nossa problemática era se na visão dos executivos entrevistados existia ou não meritocracia nas empresas em que trabalham e se isto estaria relacionado à implementação da gestão de pessoas por competências na sua empresa. Vimos que em 53\% dos casos (grupo 2) o nosso pressuposto de meritocracia e confiança se confirmam.

Nas empresas que implementaram integralmente o conceito e realmente praticam um sistema meritocrático de promoção e remuneração, se instaura uma maior confiança na organização. Desta forma que uma gestão de pessoas por competências mais eficaz (incluindo a fórmula de cálculo da remuneração que não obedeça a uma lógica de curva forçada) reforça a percepção de meritocracia na empresa gerando maior confiança dos colaboradores na liderança e também reforçando as relações de confiança entre os colaboradores e nos trabalhos em equipe.

Normalmente nesse tipo de sistema, os colaboradores têm uma percepção de maior justiça distributiva no trabalho como foi o caso de $53 \%$ dos entrevistados. Em $36 \%$ dos casos (grupos 1 e 3) existe em parte um sistema meritocrático ligado à gestão por competências, mas que precisa ser ainda bem aperfeiçoado para se gerar uma maior percepção de justiça distributiva no trabalho.

Para 11\% dos entrevistados (grupo 4) não existe na atualidade no Brasil uma percepção de meritocracia tendo em vista o momento histórico em que vive o país. Este grupo é basicamente cético. 
A percepção de $89 \%$ dos entrevistados não é a do grupo 4. A maioria dos entrevistados reconhece que existem sistemas meritocráticos no país e nas empresas em que trabalham. Que precisam ser aperfeiçoados, em maior ou menor nível de meritocracia, mas existem sim sistemas meritocráticos no todo ou em parte no nosso país na atualidade, para o grupo de alunos do Mestrado Profissional em Administração.

\section{CONCLUSÃO}

Como vimos na parte teórica deste trabalho, terminamos o mesmo com as seguintes considerações:

\section{Sobre a Meritocracia}

O constructo meritocracia está parcialmente ou inteiramente institucionalizado nas empresas, para a maioria dos entrevistados (89\% dos casos), e assim, existe sim a percepção de meritocracia neste caso. A grande maioria dos alunos do Mestrado Profissional em Administração ( $53 \%$ dos entrevistados), para eles, está em sistemas satisfatoriamente meritocráticos.

\section{Ideologia da Meritocracia}

No Brasil, para superação da atual crise socioeconômica, na visão dos entrevistados, é preciso procurar desenvolver uma sociedade que semeie condições mais igualitárias para todos, mais justa nas suas distribuições de investimentos públicos e mais meritocrática no acesso as oportunidades, por meio de investimentos educacionais para todos e o aperfeiçoamento dos sistemas de gestão de pessoas nas entidades privadas e públicas, com o foco de desenvolver capacidades que possam criar modelos mais eficientes. Na condução de um modelo de gestão por competências que identifique e reconheça de forma real e efetiva o mérito e no qual se tenha a consciência de justiça social nas diversas esferas das organizações privadas e públicas, melhorando com isso a esperança de vida e relações profissionais para todos os cidadãos. O movimento da Operação Lava Jato e o ministro Sergio Moro, na recuperação da credibilidade das instituições públicas e privadas, tem um especial papel a desempenhar para que o constructo meritocracia e a transparência organizacional sejam institucionalizados nos setores socioeconômicos e que se tornem mais justos (Dallagnol, 2017; Hasselmann, 2016; Netto, 2016). 


\section{REFERÊNCIAS}

Araujo, J. B. C., \& Cançado, V. L. (2013). Confiança e desempenho de equipes. Revista Eletrônica de Ciência Administrativa, 12(1), 75-91.

Barbosa, L. (2003). Igualdade e meritocracia: a ética do desempenho nas sociedades modernas. Rio de Janeiro, RJ: Editora FGV.

Barney, J. (1991). Firm resources and sustained competitive advantage. Journal of Management, 17(1), 99-120.

Bobbio, N. (1997). Igualdade e liberdade (2a ed.). Rio de Janeiro, RJ: Ediouro.

Creswell, J. W. (2014). Investigação qualitativa e projeto de pesquisa: escolhendo entre cinco abordagens. Porto Alegre, RS: Penso Editora.

Cummings, L. L., \& Bromiley, P. (1996). The organizational trust inventory. In R. Kramer, \& T. R. Tyler (Eds.), Trust in organizations: frontiers of theory and research. Thousand Oaks, CA: Sage.

Dallagnol, D. (2017). A luta contra a corrupção: a Lava Jato e o futuro de um país marcado pela impunidade. Rio de Janeiro, RJ: Sextante.

Duluc, A. (2000). Liderança e confiança: desenvolver o capital humano para organizações competitivas. Lisboa, Portugal: Instituto Piaget.

Dutra, J. S. (2001). Gestão por competências: um modelo avançado para o gerenciamento de pessoas. São Paulo, SP: Editora Gente.

Dutra, J. S. (2004). Competências: conceitos e instrumentos para a gestão de pessoas na empresa moderna. São Paulo, SP: Atlas.

Eisenhardt, K. M. (1989). Building theories from case study research. Academy of Management Review, 14(4), 532-550.

Fleury, M. T. L. (2002). A gestão de competência e a estratégia organizacional. In M. T. L. Fleury (Ed.), As pessoas na organização (3a ed.). São Paulo, SP: Editora Gente.

Fukuyama, F. (1996). Confiança: as virtudes sociais e a criação da prosperidade. Rio de Janeiro, RJ: Rocco.

Giddens, A. (1991). As consequências da modernidade. São Paulo, SP: UNESP.

Godoy, A. S. (1995a). Introdução à pesquisa qualitativa e suas possibilidades. RAE - Revista de Administração de Empresas, 35(2), 57-63.

Godoy, A. S. (1995b). Pesquisa qualitativa: tipos fundamentais. RAE Revista de Administração de Empresas, 35(3), 20-29.

Hasselmann, J. (2016). Sérgio Moro - A história do homem por trás da operação que mudou o Brasil. São Paulo, SP: Universo dos Livros Editora.

Hosmer, L. T. (1995). Trust: the connecting link between organizational theory and philosophic ethics. Academy of Management Review, 20(2), 379-403.

Kawai, R. M. (2017). Indicadores de desempenho em uma pequena empresa que adota um modelo de gestão baseado na confiança. Revista da Micro e Pequena Empresa, 11(1), 123- 138.
Kraemer, R. M., \& Tyler, T. R. (1996). Trust in organizations: frontiers of theory and research. Thousand Oaks, CA: Sage.

Krot, K., \& Lewicka, D. (2012). The importance of trust in manager-employee relationships. International Journal of Electronic business Management, 10(3), 224-233.

Lane, C. (1996). Theories and issues in the study of trust. In C. Lane, \& R. Bachamann (Orgs.), Trust within and between organizations: compectual issues and empirical applications. New York, NY: Oxford University Press Inc.

Leonard-Barton, D. (1992). Core capabilities and core rigidities: A paradox in managing new product development. Strategic management journal, 13(S1), 111-125.

Luhmann, N. (1980). Trust: a mechanism for the reduction of social complexity. In N. Luhmann (Ed.), Trust and power. New York, NY: Wiley.

Luhmann, N. (1996). Confianza. Barcelona, España: Antropos.

Marconi, M. A., \& Lakatos, E. M. Fundamentos de metodologia científica (5a ed.). São Paulo, SP: Atlas, 2003.

Netto, V. (2016). Lava Jato: o juiz Sergio Moro e os bastidores da operação que abalou o Brasil. Rio de Janeiro, RJ: Primeira Pessoa.

Prahalad, C. K., \& Hamel, G. (1990). The core competence of the corporation. Harvard Business Review.

Ripperger, T. (1998). Okonomik des vertauens. Tubingen, Deutschland: Mohr Siebeck.

Sandel, M. J. (2014). Justiça: o que é fazer a coisa certa (13a ed.). Rio de Janeiro, RJ: Civilização Brasileira.

Teece, D. (1992, June). Competition, cooperation and innovation: organizational arrangements for regimes of rapid technological progress. Journal of Economic Behavior and Organization, 1, 1-25.

Tzafrir, S. S., \& Harel G. H. (2002). Trust-me: a scale form measuring manager employer trustworthiness. Academy of Management Review.

Yin, R. K. (2015). Estudo de caso: planejamento e métodos (5a ed.). Porto Alegre, RS: Bookman.

Yin, R. K., \& Migueles, C. P. (2014). O papel mediador entre confiança e desempenho organizacional. Revista de Administração, 49(1), 45-58.

Yin, R. K., \& Migueles, C. P. (2016). Confiança: o principal ativo intangível de uma empresa (2a ed.). Rio de Janeiro, RJ: FGV Editora.

Zand, E. E. (1972). Trust and managerial problem solving. Administrative Science Quarterly, 17(2), 229-239.

Zanini, M. T. F. (2009). A liderança eficaz - contexto brasileiro. In C. Migueles, \& M. T. F. Zanini (Org.). Liderança baseada em valores: caminhos para a ação em cenários complexos e imprevisíveis. Rio de Janeiro, RJ: Elsevier.

Zarifian, P. (1999). Objectif compétence. Paris, France: Liaissons. 
Almir Rogério da Silva Souza

ORCID: https://orcid.org/0000-0001-5080-0864

Mestre em Administração pela Fundação Getulio Vargas (FGV). E-mail: arogersouza@gmail.com

Isabella Francisca Freitas Gouveia de Vasconcelos ORCID: https://orcid.org/0000-0001-9109-0475

Doctorat es Sciences de Gestion, HEC-Ecole des Hautes Etudes Commerciales, França (2000); Doutorado em Administração de Recursos Humanos, FGV EAESP (1997); Pós-Doutorado em Rutgers the New Jersey State University; Pesquisadora no CNAM - Conservatoire National D’Arts et Metiers, França. E-mail: ivasconcelos@yahoo.com 